\title{
PEMBUATAN GAME 2D SUSUN TERJEMAH KOSA KATA BAHASA ARAB DENGAN MEMANFAATKAN LIBRARY A* KARYA ARON GRANBERG
}

\author{
Yusuf Ansori' ${ }^{1}$, Juniardi Nur Fadila ${ }^{2}$, Fressy Nugroho ${ }^{3}$ \\ 1,2,3 Jurusan Teknik Informatika, Fakultas Sains dan Teknologi, Universitas Islam Negeri Maulana Malik \\ Ibrahim, \\ ${ }^{1} 18650041 @$ student.uin-malang.ac.id, ${ }^{2}$ juniardi.nur@uin-malang.ac.id, ${ }^{3}$ fresy@ti.uin-malang.ac.id
}

\begin{abstract}
Abstrak
Kemajuan teknologi memberikan banyak pengaruh di berbagai cabang. Salah satunya pada cabang game. Game merupakan salah satu bentuk kemajuan di bidang teknologi. Teknologi Game juga semakin berkembang dari masa ke masa dan semakin beragam maksud dan tujuan dalam pembuatannya. Dilihat dari sisi jenisnya, game dapat dibedakan game 3D dan 2D. Game 2D merupakan game dengan perspektif side-view, dimana pemain hanya dapat melihat karakter hanya dari satu sisi saja. Dari satu jenis game ini, dapat dibedakan menjadi banyak genre yang mempengaruhi karakter yang ada pada game. Pada umumnya setiap game akan terasa lebih menarik dan menantang jika terdapat non player character (NPC). Agar NPC dapat berperan sebagaimana karakter utama, maka diperlukan kecerdasan buatan. Salah satu kecerdasan buatan yang dapat digunakan adalah A* pathfinding. Dengan kecerdasan tersebut, NPC dapat mencari rute tercepat untuk berpindah dari satu titik ke titik lainnya. Pemaparan metode dan penjelasan pada penelitian disajikan secara detail dan sistematis agar mudah dipahami. Pada hasil diperlihatkan NPC yang mendekat ke karakter utama dan NPC akan menyerang karakter utama pada jarak tertentu sehingga karakter utama harus mengalahkan atau menghindari semua NPC dan menemukan setiap huruf yang tersembunyi di dalam game. Algoritma A Star (A*) terbukti dapat digunakan pada NPC di Game 2D Susun Terjemah Kosa Kata Bahasa Arab, NPC dapat mencari rute terbaik untuk medekat kepada karakter utama dan menyerang karena NPC berperan sebagai musuh dalam game.
\end{abstract}

Kata kunci : Game 2D, pathfinding, platformer, susun kata, Unity2D

\section{Pendahuluan}

Beberapa tahun terakhir, game telah bergeser dari sekedar permainan untuk menghabiskan waktu menjadi tren di setiap penduduk dunia. Menurut Fujiati dkk, teknologi game semakin berkembang. Berawal dari game konvensional sampai game saat ini yang disertai kecerdasan buatan. Game konvensional pun sudah lama ditinggalkan dan beralih ke game modern yang lebih menarik. Fujiati, Soedijono W.A., and Amborowati (2016). Game atau permainan adalah sebuah alternatif untuk sarana hiburan bagi orang tua, muda, maupun anak - anak dengan genre yang bermacam-macam jenisnya, seperti petualangan, arcade, teka-teki dan lain sebagianya dengan model $3 \mathrm{D}$ ataupun $2 \mathrm{D}$ AZIF (2016).

Indonesia termasuk negara dengan peminat game yang tinggi. Dapat diketahui dari lingkungan sekitar yang mayoritas masyarakat memainkan game baik sebagai hiburan atau sebuah kegiatan rutin. Hal ini juga dapat menjadi peluang bisnis yang menjanjikan bagi para pembuat game Pramono (2017). Menurut surat kabar online INews.com pada tahun 2019 Indonesia mampu menghasilkan 1,1 miliar USD dari sektor industri game Sarasa (2020).
Game tidak hanya digunakan untuk menghilangkan rasa jenuh tetapi juga dapat digunakan sebagai sarana pendidikan. Pada umumnya, game yang dibuat dapat meningkatkan kreatifitas pemain dengan menyelesaikan setiap level pada game tersebut Haris, and Mawardi (2018). Level di dalam sebuah game juga menghadirkan tantangan baru bagi pemainnya. Game akan terasa dinamis dan memiliki keunikan pada setiap level. Hal ini mendorong pemain untuk terus berfikir agar dapat menyelesaikan tantangan pada level tersebut.

Keunikan lain dari teknologi game adalah bentuknya yang bervariasi. game dapat berupa tampilan 3D yang memberikan efek lebih nyata dalam sebuah permainan. Selain itu juga terdapat bentuk 2D, dimana perspektif tampilan hanya dari salah satu sisi saja (side-view). Game 2D juga disebut game dengan genre platformer. Game ini mulai dikenalkan pada tahun 1980 dan terus berkembang sampai saat ini. salah satu pengembangannya adalah penerapan kecerdasan buatan (artificial intelligence) pada game tersebut. Pada genre platformer, kecerdasan buatan dapat diterapkan pada lingkungan maupun karakter yang dikontrol oleh computer atau NPC (Non-Player Character) AZIF (2016) 
Metode A Star (A*) adalah salah satu algoritma kecerdasan buatan yang sering digunakan dalam pembuatan game dengan konsep Non-Player Character (NPC). Metode A* yang banyak digunakan untuk NPC adalah pathfinding. Pathfinding adalah proses pencarian rute tercepat yang dapat dilewati untuk menuju ke satu titik dan titik selanjutnya. Pathfinding diperlukan jika terdapat rintangan yang mengharuskan NPC untuk berbelok dan menentukan jalur lainnya, sehingga diperlukan sebuah keputusan untuk menentukan jalur terbaik agar dapat sampai ke titik target Theosaksomo (2017).

Peranan penting dari Non Player Character dapat dilihat dari peran yang dijalankan. NPC mampu berperan menjadi menjadi musuh ataupun teman bagi player dan memberikan informasi yang berhubungan dengan permainan. Dengan menambahkan sebuah kecerdasan buatan yang diberikan kepada NPC, menjadikan game terasa lebih seru dan menantang AZIF (2016).

Pembuatan algoritma pathfinding cukup sulit dan kompleks sehingga membutuhkan waktu untuk memahami dan membuatnya. Salah satu alternatif yang dapat digunakan adalah library $\mathrm{A}^{*}$ yang dibuat oleh Aron Granberg, yaitu "Astar Pathfinding Project". Library dini tersedia free version dan pro version dan semuanya dapat digunakan sesuai kebutuhan. Metode A* pathfinding secara lengkap disajikan dalam library ini Theosaksomo (2017).

Banyak penelitian yang telah menerapkan library $\mathrm{A}^{*}$ ini. Setiyawan, Aditya dkk meneliti tentang penerapan pathfinding menggunakan algoritma $A^{*}$ pada non player character (NPC) di game, hasilnya menunjukan adanya efektivitas dari node yang dilewati. Rute player NPC dalam melakukan eksplorasi peta dalam game menunjukkan rute jalur yang sama dengan perhitungan manual menggunakan algoritma $A^{*}$ dan merupakan rute tercepat yang bisa dilalui Setiawan, Aditya.Harsadi and Siswanti (2019). Penelitian lain yang dilakukan oleh Agung Pamungkas dkk menyebutkan bahwa algoritma A Star berhasil digunakan dalam sebuah game edukasi labirin untuk mencari rute tercepat menuju pintu keluar Pamungkas. dkk (2011). Kemudian penelitian yang dilakukan Kikik menerapkan algoritma A Star pada permainan ular tangga, dimana ular akan menuju makanan yang ditempatkan secara acak oleh sistem dengan menggunakan rute terpedek. Hasilnya ular dapat menuju titik makanan dengan menggunakan jalur terpendek secara heuristik.

Pada penelitian ini, penulis mencoba menerapkan library tersebut pada game susun terjemah kosa kata bahasa arab. Library ini akan diterapkan pada karakter NPC sebagai musuh yang harus dihadapi untuk dapat menyelesaikan setiap level dan memecahkan semua tugas yang diberikan.

\section{Tinjauan Pustaka}

Game atau permainan adalah suatu bentuk hiburan yang bersifat interaktif. Diantara contoh hiburan lain, seperti menonton televisi, membaca, dan pergi ke teater adalah bentuk hiburan pasif. Permainan pada zaman sekarang sudah lebih berkembang dari sebelumnya, game ditempatkan pada sebuah dunia buatan yang diatur melalui aturanaturan (rules) tertentu. Aturan yang dimaksud dapat menentukan tindakan atau langkah yang pemain dapat dan tidak dapat lakukan dalam sebuah game Pramono (2017)

Game platformer merupakan jenis game yang bergerak secara 2D dalam axis $\mathrm{x}$ dan $\mathrm{y}$, dan jenis game dengan perspektif side-view. Axis x sebagai gerak player maju dan mundur, sedangkan axis y untuk ketinggian yang dapat dicapai player ketika melompat Theosaksomo (2017).

Game akan semakin menarik dan tidak membosankan jika game yang dibuat sesuai dengan kemampuan player. Salah satu unsur yang dapat digunakan untuk mewujudkan game yang bersifat adaptif adalah dengan system leveling dan terdapat kecerdasan buatan di setiap level Cahyono Agus (2015)

Secara sederhana kecerdasan buatan dapat di definisikan dengan seperangkat sifat atau pikiran. Sifat yang dimaksud adalah kemampuan untuk merencanakan, memecahkan masalah, dan secara umum akal pikiran. Kemampuan tersebut digunakan untuk membuat keputusan yang tepat dari serangkaian input yang diberikan.Heriyanto, Kumalasarinurnawati, and Andayati (2018).

Algoritma $A^{*}$ merupakan metode untuk menyelesaikan masalah dengan menggunakan graph untuk perluasan ruang statusnya. Dengan kata lain digunakan untuk menyelesaikan permasalahan yang bisa direpresentasikan dengan graph. A* menggunakan fungsi heuristik, algoritma ini mengoptimalkan langkah dengan menentukan langkah terbaik dan membuang langkah-langkah yang tidak perlu. Dengan kata lain algoritma ini adalah melakukan traversal satu per satu pada tiap simpul untuk memperoleh lintasan terpendek pada suatu graph Pamungkas, Widiyanto, and Angreni (2011). Suatu fungsi heuristik dapat dikatakan baik, apabila dapat memberikan biaya perkiraan yang mendekati biaya sebenarnya. Fungsi heuristik akan semakin baik jika semakin mendekati biaya sebenarnya. Metode A* dapat dirumuskan dengan :

$$
\mathbf{f}(\mathbf{n})=\mathbf{g}(\mathbf{n})+\mathbf{h}(\mathbf{n})
$$

$$
\begin{aligned}
& \text { Keterangan : } \\
& \mathrm{f}(\mathrm{n})=\text { solusi biaya estimasi termurah verteks } \mathrm{n} \\
& \text { untuk mencapai tujuan. } \\
& \mathrm{g}(\mathrm{n})=\text { biaya path / perjalanan } \\
& \mathrm{h}(\mathrm{n})=\text { biaya estimasi dari verteks } \mathrm{n} \text { ke tujuan. }
\end{aligned}
$$

Algoritma A Star berjalan dengan melakukan pengecekan kelayakan nilai $\mathrm{f}(\mathrm{n})$ yang dibutuhkan 
untuk mencapai simpul tujuan dari simpul awal. Nilai $\mathrm{f}(\mathrm{n})$ adalah penjumlahan dari nilai sebenarnya $\mathrm{g}(\mathrm{n})$ dan nilai perkiraan $\mathrm{h}(\mathrm{n})$.

Algoritma ini memberikan efek kecerdasan terhadap sebuah karakter NPC untuk dapat bergerak dan berperilaku sebagaimana karakter utama pada sebuah game.

Algoritma A star digunakan karena tingkat akurasinya yang tinggi dan penampilannya yang baik saat menggunakan heuristic dan terkenal karena penggunaannya yang luas di berbagai bidang Gede Wahyu (2018)

Model NPC merupakan objek yang tidak menjadi pusat perhatian dan dapat membuat keputusan sendiri tanpa control dari player. NPC hanya bergerak pada jangkauan wilayah yang sudah ditentukan dalam game Kurniawan, F (2016). NPC juga memiliki kemampuan untuk berinteraksi dengan karakter utama dan kemampuan improvisasi untuk melakukan suatu tindakan kepada karakter utama Asmiatun (2016)

Kemudian peneliti menggunakan software unity game engine untuk merancang dan membuat game dan menerapkan algoritma $\mathrm{A}^{*}$. Unity game engine adalah software yang digunakan untuk membuat dan mengembangkan game baik 3D maupun 2D. Selain itu, software ini juga dapat digunakan untuk pembuatan konten yang interaktif lainnya seperti, visual arsitektur, video game 3D dan real-time 3D animasi Maaruf (2016).

Selain kemudahan menggunakan software Unity yang telah disebutkan, unity game engine juga merupakan software gratis yang memiliki banyak fitur FIRMANSYAH, M (2016)

\section{Metode Penelitian}

Penelitian ini terbagi menjadi beberapa tahapan. Tahapan dibuat secara sistematis pada perangkat lunak. Dimulai dengan membuat naskah dan alur rancangan game, yaitu membuat tema dari game, kemudian menetukan jenis (genre) game, merencanakan misi yang akan dijalankan, membuat rancangan karakter dan objek, membuat rancangan flowchart algortima $A^{*}$ pathfinding untuk NPC, representasi algoritma $\mathrm{A}^{*}$, serta perencanaan struktur menu utama dari game tersebut.

\subsection{Rancangan Karakter dan Objek}

Karakter pada game 2D lebih sederhana daripada pada game 3D, sehingga tidak membutuhkan waktu yang lama dalam pembuatannya. Walaupun demikian, kelebihan dari 2D adalah sangat mudah diterima oleh kalangan anak-anak karena tidak terlalu membutuhkan banyak tombol kontrol Rangga and Putra (2013). Karakter utama pada game adalah perwujudan dari player. Dan objek lain merupakan bagian dalam game yang memiliki peran masing-masing. Musuh (NPC) berperan sebagai penghalang karakter utama untuk menyelesaikan level, dan objek pohon menjadi bagian dari lingkungan yang menjadi pelengkap game. Perancangan karakter, musuh dan objek pada game Susun Terjemah Kosa Kata Bahasa Arab dapat dilihat pada Tabel 1. Perancangan Karakter, Musuh, dan Objek Lingkungan

Tabel 1. Perancangan Karakter, Musuh, dan Objek Lingkungan

\begin{tabular}{|c|c|c|}
\hline No & Gambar & Ket. \\
\hline 1 & & $\begin{array}{c}\text { Karakter } \\
\text { utama }\end{array}$ \\
\hline 2 & & $\begin{array}{c}\text { Musuh } \\
1\end{array}$ \\
\hline 3 & & $\begin{array}{c}\text { Musuh } \\
2\end{array}$ \\
\hline 4 & & $\begin{array}{l}\text { Objek } \\
\text { pohon }\end{array}$ \\
\hline 5 & & $\begin{array}{c}\text { Objek } \\
\text { semak- } \\
\text { semak }\end{array}$ \\
\hline
\end{tabular}

\subsection{Flowchart Game}

Seorang player yang memainkan game akan melalui alur seperti pada Gambar 1. Diagram Alir Game.

Pemain harus memaikan game sesuai alur :

- Memulai game sehingga menuju menu utama dan dapat memilih setiap tombol yang terdiri dari play, petunjuk permainan, tentang permainan 
dan keluar. Jika memilih tombol keluar maka permainan selesai.

- Ketika player memilih tombol play maka permainan akan dimulai dan masuk ke tingkatan level secara berurutan. Jika player tidak bias menyelesaikan, maka permainan akan berakhir dan mengulanginya kembali dari lever pertama.

- Jika player berhasil menyelesaikan misi pada setiap level maka permainan akan berakhir dan kembali ke menu utama.

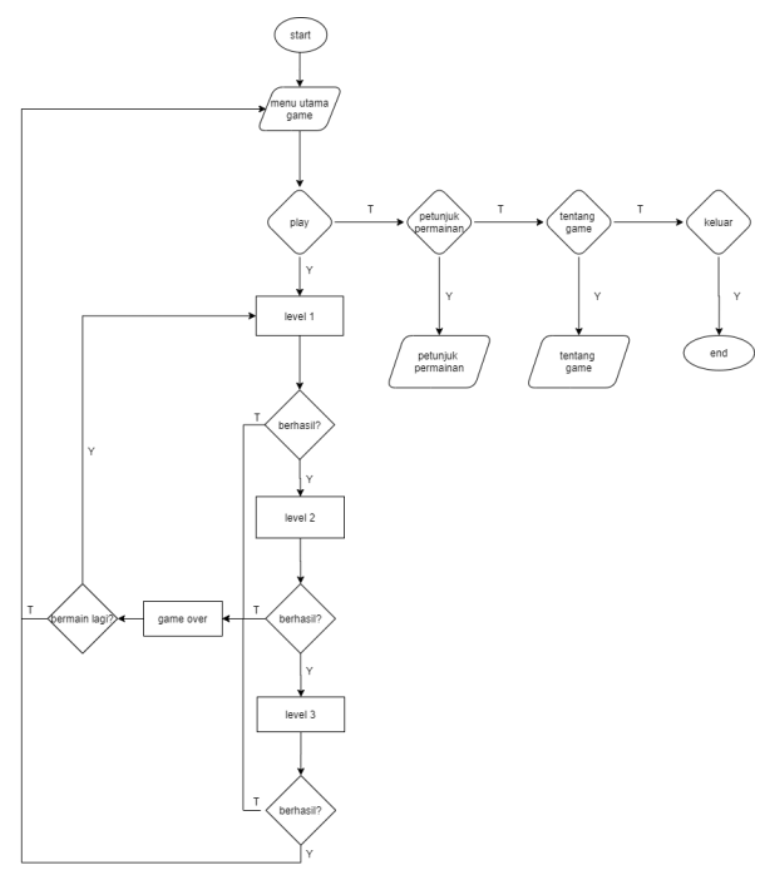

Gambar 1. Diagram Alir Game

\subsection{Flowchart $\mathrm{A}$ *}

Pada bagian ini merupakan perancangan Algoritma $A^{*}$ bekerja dalam mencari rute paling optimum pada area. Algoritma ini bekerja dari titik awal ke titik tujuan dengan mencari jalan dengan akumulasi bobot terendah. Proses pemberian bobot pada node-node sangatlah penting dalam menentukan hasil pencarian. Proses mencari node dengan nilai terkecil ini dilakukan berulang-ulang sampai menemukan node tujuan. Untuk diagram alir dari Algoritma A* ditunjukan pada Gambar 2. Diagram Alir Algoritma A*

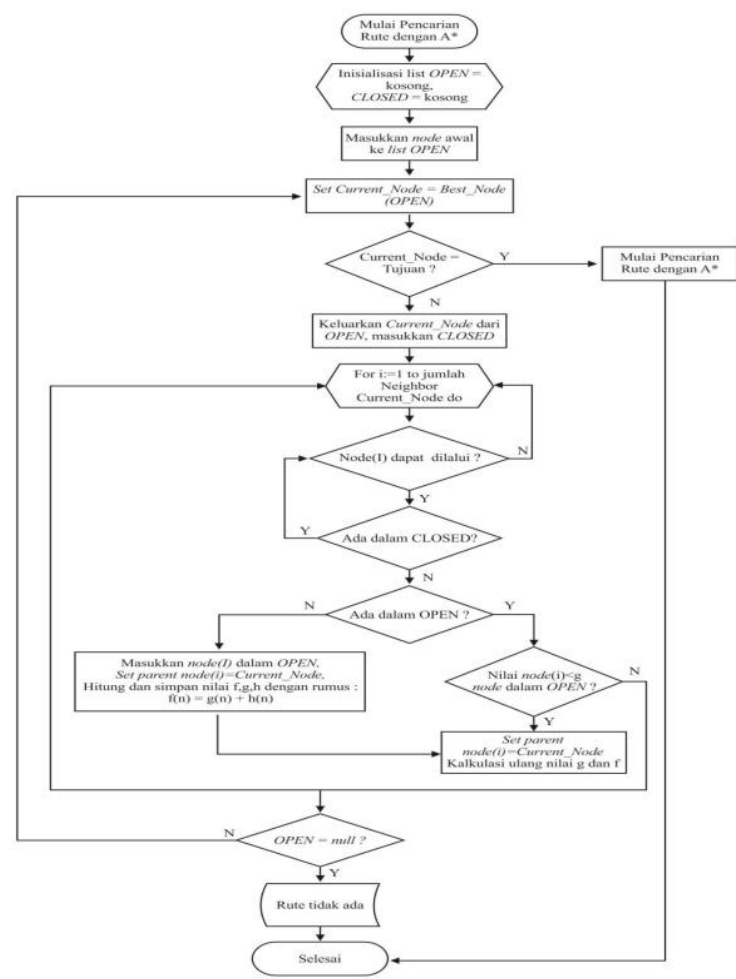

Gambar 2. Diagram Alir Algoritma A*

\subsection{Flowchart A* pada NPC}

Diagram alir ini merupakan bagian penerapan Algoritma $A^{*}$ pathfinding pada karakter NPC. Penerapan Algoritma A* pertama diambil titik awal NPC yang kemudian dilakukan perhitungan cost terendah dan melakukan pergerakan ke karakter utama. Untuk diagram alir dari perancangan Algoritma A* pada musuh dapat dilihat pada Gambar 3. Diagram Alir A* pada NPC

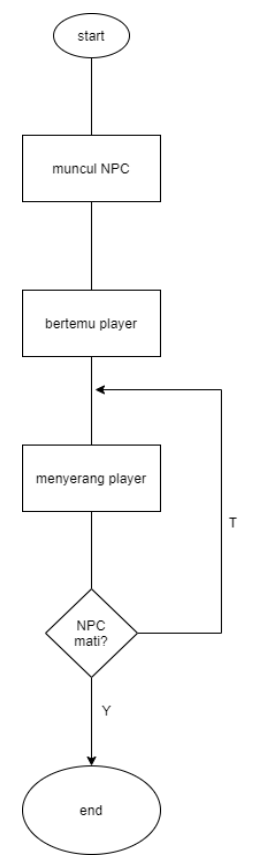

Gambar 3. Diagram Alir A* pada NPC 


\subsection{Perencanaan Struktur Menu}

Menu utama di tampilkan pada saat membuka game. Pada menu utama game dirancang 4 button yaitu Play, Petunjuk Permainan, Tentang Game dan Keluar. Rancangan urutan tombol pada menu utama ditunjukkan pada Gambar 4. Struktur Menu

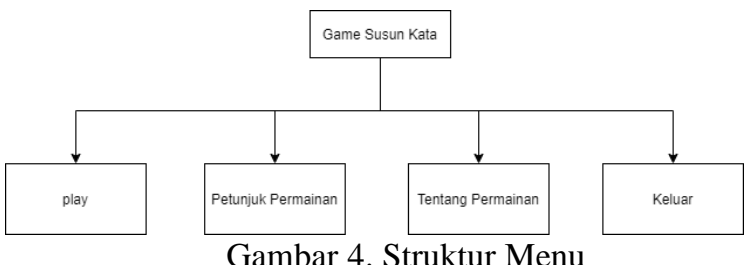

Untuk memulai game, pemain memilih menu Play. Menu Petunjuk Permainan menampilkan informasi tata cara memainkan game dan menyelesaikan misi pada level. Pada menu Tentang Permainan berisi informasi tentang game yang dibuat. Dan menu Keluar untuk keluar dari game.

\section{Hasil dan Pembahasan}

Pada bagian ini memuat hasil dari game yang dibuat dan pembahasan dari bagian-bagian yang dibuat

\subsection{Tampilan Menu Utama}

Menu utama adalah menu yang pertama kali muncul saat membuka game. Terdapat tombol play yang berfungsi untuk memulai permainan, tombol Info, tombol Tentang Permainan berada disebelah kiri atas dan tombol Kembali untuk keluar dari game. Desain dari menu utama dapat dilihat pada Gambar 5. Menu Utama

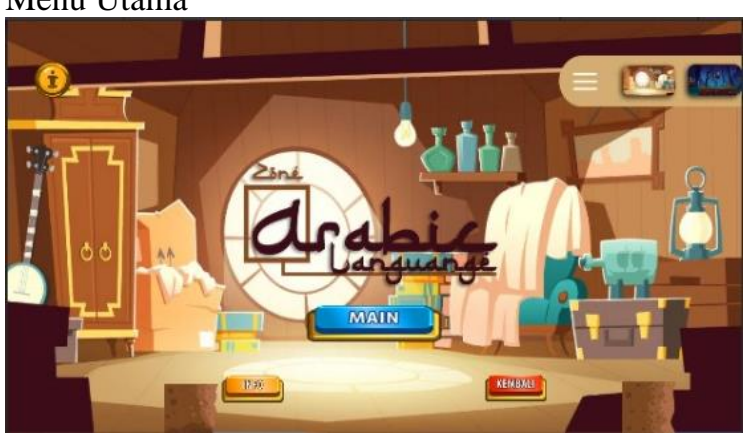

Gambar 5. Menu Utama

\subsection{Tampilan Menu Petunjuk Permainan}

Pada menu Petunjuk Permainan ditampilkan cara bermain game ini. Diharapkan pemain dapat memahami sehingga dapat menyelesaikan misi pada setiap levelnya. Gambar 6. Menu Petunjuk Permainan

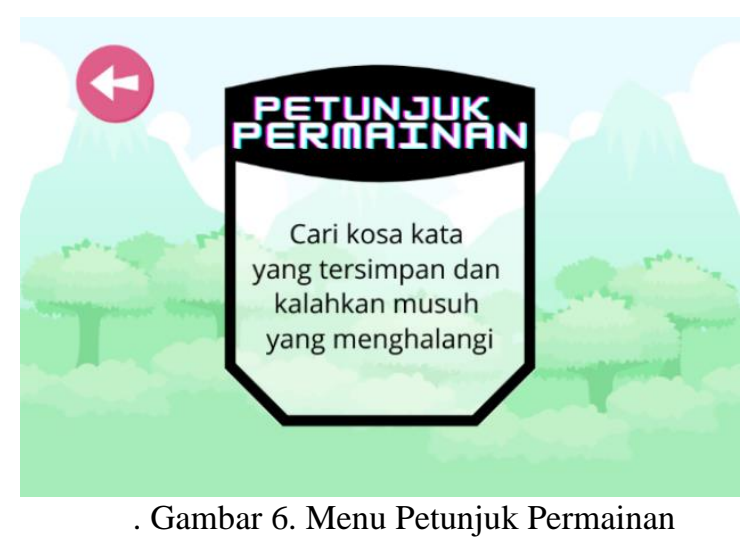

\subsection{Pengujian Mulai Game}

Tombol play akan mengarahkan pemain untuk masuk ke permainan. Karakter utama berada pada sisi atas dan mengamati keadaan sekitar. Seketika karakter utama bergerak, musuh kelelawar akan mulai mendekat dan menyerang pemain. Musuh kelelawar dapat bergerak dengan adanya kecerdasan buatan di dalamnya.

Algoritma A Star (A*) bekerja dengan mencari jalan terpendek menuju objek target. Dengan algoritma ini, komputer akan menjalankan peran NPC dan mencari rute tercepat dan terefisien.

Pada saat game dimulai, terdapat NPC berupa kelelawar dan slime. NPC kelelawar menggunakan A* untuk mendekati karakter utama, sehingga karakter utama harus menghindari serangan dari kelelawar dan mencari setiap huruf yang tersembunyi. Kelelawar akan selalu mengikuti karakter utama. Sedangkang NPC slime hanya bergerak bolak-balik di area yang sudah ditentukan. Jika karakter utama mengenai atau dikenai oleh musuh, secara otomatis akan terbunuh dan mulai mencari lagi setiap kosakata yang tersimpan dalam game. Karakter utama dapat mengeluarkan senjata berupa bubble yang dapat ditembakkan secara otomatis ketika NPC berada di jarak tertentu sebagai pertahanan diri. Ketika semua NPC sudah dikalahkan dan belum menemukan huruf yang dicari karakter harus melanjutkan ke halaman berikutnya melalui pintu yang berada di pojok kanan atas. Setiap level memiliki tingkat kesulitan yang berbeda sehingga memengaruhi waktu pencarian kosakata yang ada pada game. Tampilan pada saat in-game dapat dilihat pada Gambar 7. Game Play.

Garis hijau merupakan rute tercepat yang dilalui oleh NPC. Rute tersebut didapat dari perhitungan pada algoritma $\mathrm{A}^{*}$ secara heuristic. Pada NPC yang berada di bawah komponen Seeker dapat mengatur perilaku umum dari NPC untuk mengikuti jalur pada graf, pada gambar terdapat sebuah objek yang memiliki tag tanah yang memiliki box collider $2 d, \mathrm{~A}^{*}$ mengatur NPC untuk menghindari tabrakan dengan objek tersebut dan memilih mencari rute lain yang dapat dilalui. Garis hijau akan mengikuti gerak dari karakter utama, karena karakter utama 
merupakan objek yang dituju oleh NPC dengan A* pathfinding. Rute NPC menuju objek akan berubah sesuai dengan posisi dari objek.

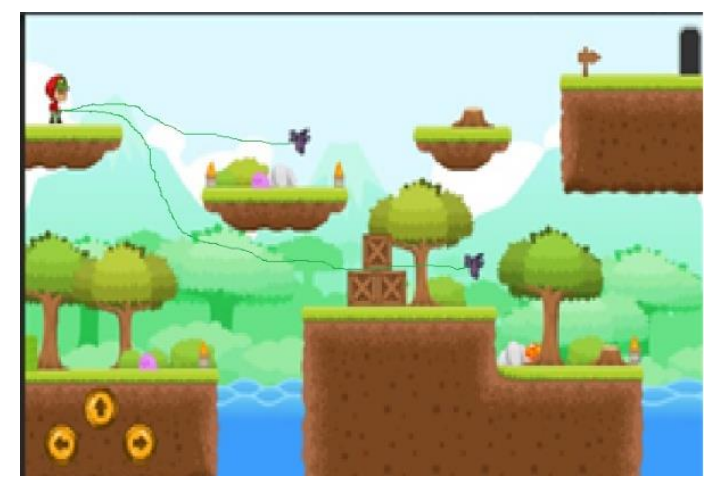

Gambar 7. Game Play

\section{Kesimpulan dan Saran}

Game 2D Susun Terjemah Kosa Kata Bahasa Arab dibuat menggunakan software unity. Game ini menggunakan perspektif side-view, sehingga karakter hanya dapat bergerak pada axis $\mathrm{x}$ dan $\mathrm{y}$ saja. Penggunaan library A* karya Aron Granberg pada NPC menjadikan game lebih menarik dan menantang. Pada gambar 7 telah diperlihatkan contoh dari pergerakan musuh yang telah diberi kecerdasan buatan sehingga memberikan sedikit gambaran tentang bagaimana algoritma $\mathrm{A}^{*}$ bekerja pada karakter NPC.

Penelitian ini masih terdapat banyak kekurangan. Menyadari hal tersebut peneliti berharap penerapan algoritma $\mathrm{A}^{*}$ pada game 2 dimensi terus dilakukan pada penelitian-penelitian berikutnya dengan konsep yang lebih menarik dan adaptif.

\section{Daftar Pustaka:}

Asmiatun, Siti. 2016. "Penerapan Algoritma Collision Detection Dan Bayesian Untuk Strategi Menyerang Jarak Dekat Pada Npc (Non Player Character)Menggunakan Unity 3D." Jurnal Transformatika 14(1): 6.

AZIF, FAIS ZHARFAN. 2016. "IMPLEMENTASI AI MENGGUNAKAN LIBRARY A * PATHFINDING PROJECT OLEH ARON GRANBERG DAN TINGKAT KEBERANIAN LAWAN PADA GAME PLATFORMER ASHES OF RESURGENCE." Skrpisi.

Cahyono, Agus. 2015. "Pencarian Posisi Pemain Oleh Karakter Musuh (Pathfinding) Dengan Metode A Star (A*) Pada Game Pembelajaran Benda Prasejarah.” Skripsi.

Darius Andana Haris, Viny Christanti Mawardi. 2018. "Pembuatan Game Platformer Multiplayer 'The Constin's Prophecy."' Jurnal Ilmu Komputer dan Sistem Informasi 6(2): 135-40.

Fujiati, Bambang Soedijono W.A., and Armadiyah
Amborowati. 2016. "Perancangan Pengembangan Game Ular Melawan Ulat Menggunakan Augmented Reality." Eksplora Informatika 6(1): 1-8. https://eksplora.stikombali.ac.id/index.php/eksplora/article/view/99/8 2.

Gede Wahyu Antara Dalem, Ida Bagus. 2018. "Penerapan Algoritma A* (Star) Menggunakan Graph Untuk Menghitung Jarak Terpendek." Jurnal RESISTOR (Rekayasa Sistem Komputer) 1(1): 41-47.

Heriyanto, Edi, Erna Kumalasarinurnawati, and Dina Andayati. 2018. "Skripsi Implementasi Kecerdasan Buatan Pada Game Menggunakan Metode Pathfinding Dengan Game Engine Unity3D." Jurnal SCRIPT 5(2): 56-62. https://ejournal.akprind.ac.id/index.php/script/ article/view/641.

Kurniawan, Fachrul. 2016. "Game Bahari Menggunakan Algoritma Fisher Yates Suffle Sebagai Pengacak Posisi NPC." Matics 7(2): 71.

M.FIRMANSYAH. 2016. "PENERAPAN ALGORITMA A* (A-STAR) PADA PERMAINAN SPY HUNTER.” skripsi.

Maaruf, Kikik Chomsan. 2016. "KECERDASAN BUATAN MENGGUNAKAN ALGORITMA A STAR ( A *) DALAM PERMAINAN ULAR TANGGA ( SNAKE 3D )." : 6-7.

Pamungkas, A, EP Widiyanto, and R Angreni. 2011. "Penerapan Algoritma A* ( A Star ) Pada Game Edukasi The Maze Island Berbasis Android." Indonesian Journal of Computing and Cybernetics Systems (x): 1-11. https://jurnal.ugm.ac.id/ijccs.

Pramono, Agung Widhi. 2017. "Pembuatan Game Petualangan Si Jupri Unity 3D Dengan Menggunakan Metode A." JATI (Jurnal Mahasiswa Teknik Informatika) 1(1): 506-13.

Rangga, Ardiana, and Pradana Putra. 2013. "Mempercantik Tampilan Game 2D Menjadi 3D De Kronik Van Diponegoro Menggunakan Teknik Mode 7." Jurnal Teknik Elektro Unnes 5(2): 102-6.

Sarasa, Agung Bakti. 2020. "Industri Game Raup Pendapatan USD1,1 Miliar Di Indonesia, Tantang Developer Lokal." https://jabar.inews.id/berita/industri-gameraup-pendapatan-usd11-miliar-di-indonesiatantang-developer-lokal.

Setiawan, Aditya.Harsadi, Paulus, and Sri Siswanti. 2019. "Penerapan Pathfinding Menggunakan Algoritma A* Pada Non Player Character (NPC) Di Game." Jurnal Ilmiah SINUS 17(2): 39.

Theosaksomo, David. 2017. "Pembuatan Pathfinding Untuk Game Platformer Dengan Memanfaatkan Library A* Karya Aron Granberg Pada Unity Engine.” Institut Teknologi Bandung. 